\title{
Individual differences in paranormal beliefs: The differential role of personality aspects
}

\author{
Bruno Chauvin ${ }^{1}$ \& Etienne Mullet $^{2}$
}

\begin{abstract}
Personality is among the most studied correlates of belief in the paranormal. There is, however, some inconsistency in their association. The purpose of the present study was to provide a more clear view of how paranormal beliefs are associated with personality by (1) using a psychometrically sound instrument for assessing belief in the paranormal, and (2) investigating the differential role in paranormal beliefs of the two lower-level aspects of each Big Five domain. French citizens completed a modified version of the Revised-Paranormal Belief Scale and the Big Five Aspect Scales. A six-factor model of paranormal beliefs displaying strong psychometric properties was identified. Correlations between personality and paranormal beliefs were stronger at the aspect level than at the domain level. Consistent with our differential prediction hypothesis, the effect of one aspect was not the same as another aspect of the same broad domain of personality on belief in the paranormal. Withdrawal, Openness, Industriousness, and Assertiveness did a good job of predicting belief in the paranormal, while Volatility, Intellect, Orderliness and Enthusiasm were not predictors of such beliefs. Overall, these results emphasize the importance of considering lower levels of the personality hierarchy in attempting to understand paranormal beliefs.
\end{abstract}

Keywords Personality · Big five aspect scales (BFAS) · Belief in the paranormal · Confirmatory factor analysis $\cdot$ Path analysis

Belief in paranormal phenomena - defined as anomalous experiences involving processes that in principle are physically impossible as well as outside the realm of human capabilities as presently conceived by conventional scientists (Irwin 1993) - is widespread around the world. According to Lindeman and Aarnio (2006), more than a third of Americans still believe in psychic powers and extrasensory perception (see also Irwin 2009). With such a prevalence of paranormal beliefs, attention has quickly begun to focus on the individual differences associated with such beliefs, including personality (see Irwin 1993,2009 , for reviews). Personality is among the most studied correlates of belief in the paranormal, probably because most of paranormal beliefs fulfill psychological needs which derive from specific patterns of personality traits and/or involve constructs conceptually related to personality. For

* Bruno Chauvin

bruno.chauvin@unistra.fr

1 Department of Psychology, University of Strasbourg, Goethe 12, F-67000 Strasbourg, France

2 Institute for Advanced Studies (EPHE), Paris, France example, religious (e.g., God existence) or superstitious (e.g., lucky charm) beliefs may provide more neurotic or less emotionally stable individuals with perceived control or resources for adjustment (Irwin 1993; Risen 2016). Beliefs about magical practices (e.g., witchcraft) or precognition (e.g., clairvoyance) fit fully with open-mindedness, fantasy proneness, or willingness to entertain unconventional values, all of which are characteristics typically associated with individuals high in Openness/ Intellect (Saucier and Skrzypinska 2006; Smith et al. 2009).

What is disputed, however, is the magnitude of the relationship between personality and paranormal beliefs. Mixed evidence exists for every broad dimension of personality except for Agreeableness which is not associated with paranormal beliefs (e.g., MacDonald 2000). While some studies have found that paranormal believers score high in Neuroticism (Wiseman and Watt 2004), Openness/Intellect (Saucier and Skrzypinska 2006), Extraversion (Thalbourne and Haraldsson 1980), and low in Conscientiousness (Zingrone et al. 1998-99), others, in contrast, have reported no such relationship between belief in the paranormal and Neuroticism (Willging and Lester 1997), Extraversion (Williams et al. 2007), and Conscientiousness (MacDonald 2000), or even a negative relation with Openness/Intellect (Swami et al. 2009). 
Of course, inconsistency in the association between the broad-bandwidth dimensions of personality and paranormal beliefs may in part derive from differences in how studies had operationalized these constructs (Rattet and Bursik 2001). On this point, a major concern has been, and still is, related to the Revised-Paranormal Belief Scale (R-PBS, Tobacyk 2004). Despite its widespread use across the world to assess the pattern of paranormal beliefs for a population and to examine relationships between such beliefs and various psychological features (e.g., Lindeman et al. 2015), the RPBS has come under criticism on various psychometric fronts. First, there is a considerable debate concerning the correct dimensionality of the R-PBS. Whereas some researchers (e.g., Tobacyk 2004) has consistently advocated seven orthogonal factors (Traditional Religious Belief, Psi belief, Witchcraft, Superstition, Spiritualism, Extraordinary Life Forms, and Precognition), others have counter-argued in favor of five oblique factors - in particular with a mixed spiritualism-psi factor (e.g., Lawrence et al. 1997), or six relatively independent factors (Utinans et al. 2015). Still other researchers (e.g., Lindeman and Aarnio 2006) have more specifically examined whether the paranormal belief factors are manifestations of one higher-order construct or whether they express independent dimensions. Having observed high intercorrelations between factors, they showed that these beliefs could be best described by one higher-order factor indicating a general tendency to believe in paranormal phenomena. Another concern is related to the psychometric properties of the R-PBS. A less than acceptable fit between observed data and model (as recommended by $\mathrm{Hu}$ and Bentler 1999) has been reported for the R-PBS, regardless of the tested version (see Lawrence et al. 1997, or Utinans et al. 2015, for details). Several items had low loadings (i.e. <.40) on their intended factor (e.g., Bmind reading is not possible ${ }^{\wedge}$ ); other items were associated with unjustified cross-loadings (e.g., Bthe soul continues to exist though the body may $\left.\mathrm{die}^{\wedge}\right)$; still other items failed to reflect their latent construct (e.g., Bthere is life on other planets ${ }^{\wedge}$ does not look like it taps into Extraordinary Life Forms) (see Lange et al. 2000, for details). Reliability estimates for the superstition and extraordinary life forms subscales have proven to be less than sufficient (Cronbach's $\alpha$ coefficients $<.70$ or even .60) (Aarnio and Lindeman 2005; Lange et al. 2000). In sum, key concerns about the dimensionality and the psychometric properties of the R-PBS have consistently been raised in the literature.

Additionally, another plausible explanation could be that the lower-level components of each broad dimension of personality as developed by De Young et al. (2007) have distinct relationships with belief in the paranormal and most of its components. In their study, they showed that each of the five broad dimensions can be decomposed into two narrower aspects representing related but separable traits. The lower-order aspects of Neuroticism are Withdrawal - corresponding to anxiety, fearfulness, and vulnerability, and Volatility - corresponding to emotional lability and irritability. For Openness/ Intellect, the two aspects are Openness - as characterized by fantasy, imagination, and artistic values, and Intellect - as characterized by quickness and ingenuity. The two aspects of Conscientiousness are Industriousness - encompassing traits like purposefulness, self-discipline and deliberation, and Orderliness - encompassing traits like order and perfectionism. The lower-order aspects of Extraversion are Assertiveness - corresponding to agency, social dominance, and provocativeness, and Enthusiasm - corresponding to gregariousness and sociability. The lower-order aspects of Agreeableness are Compassion - corresponding to warmth and sympathy, and Politeness - corresponding to cooperation and straightforwardness. Consistent with this breakdown, we argue that, conceptually, belief in the paranormal involves constructs that do not correspond well to this or that personality dimension as a whole but fit better with one lower-level aspect of each broad dimension (over the other). Specifically, previous research (e.g., Irwin 1993; Saucier and Skrzypinska 2006) has consistently stated that paranormal beliefs (especially spiritual beliefs like reincarnation) may provide a buffer against mortality-based anxiety and thus enhance a sense of safety and security, which is much more connected with the withdrawal aspect of Neuroticism than with its volatility aspect. In addition, most of paranormal beliefs (ranging from belief in ghosts, witches, and extraordinary life forms to astrology and clairvoyance) appear to be both inherently and empirically much closer to the openness aspect of Openness/ Intellect (as characterized by fantasy proneness and imagination) than to its intellect aspect (De Young et al. 2016; Irwin 1993). Another key feature of paranormal believers is their high intuitiveness; that is, the tendency to rely heavily on their intuitive impressions or personal experiences and to engage more in intuitive thinking than in analytic thinking for processing information (Aarnio and Lindeman 2005; Risen 2016). The intuitive mode of thinking coincides much more with the (low) industriousness aspect of Conscientiousness which consists of traits such as (low) purposefulness and (low) deliberation than with its (low) orderliness aspect. Finally, paranormal beliefs such as psi beliefs (e.g., psychokinesis) or precognition (e.g., ability to predict the future) challenge the conventional view about human's cognitive limitations by assigning supernatural skills to some superior beings. As such, these beliefs are more likely to represent the tendency toward provocativeness and social dominance - both of which are traits from the assertiveness aspect of Extraversion, than the tendency toward social affiliation (Kennedy 2005).

Accordingly, the purpose of the present study is to provide a more clear view of how people's paranormal beliefs are associated with their personality. Given both reliability and validity of the R-PBS represent required conditions to examine relationship between the personality characteristics of 
individuals and their endorsement of paranormal beliefs (Brown 2006), our first aim is to identify an alternative factor structure which represents a psychometrically sound version of the R-PBS. Our second aim is to investigate whether such relationship depends on the content of the personality measure, in particular what lower-level aspect of the personality dimension (as defined by De Young et al. 2007) is under consideration (except for Agreeableness for which no relationship is expected). Our first hypothesis is that stronger correlations between personality and paranormal beliefs will appear at the aspect level than at the Big Five level. Our second hypothesis states that the two lower-level aspects of each dimension will differentially predict belief in the paranormal, such that the effect of one aspect will not be the same as another aspect. Specifically, Withdrawal, Openness, Industriousness, and Assertiveness will better predict paranormal beliefs than will Volatility, Intellect, Orderliness, and Enthusiasm, respectively.

\section{Method}

\section{Participants and Procedure}

Our sample consisted of 767 French citizens. They were 388 women and 379 men, ranging from 15 to 87 years $(\mathrm{M}=38.2$, $\mathrm{SD}=16.6$ ). These people were recruited as follows: they were contacted during daylight hours in the main streets of Nantes, a town of half-a-million inhabitants located in the west of France. The individuals approached were told that our research team was conducting a survey on belief in paranormal phenomena and were given some examples of the questions.

Data were collected individually during at-home sessions where each participant was asked to complete a French version of two questionnaires. In designing the French version, the authors followed the guidelines proposed in the literature on cross-cultural methodology (Brislin 2000): independent/ blind/back-translation, educated translation, small-scale pretests. A translation was executed by two bilingual translators. A first bilingual translated the English items into French, with feedback from the first author of the paper (BC). Next, a second bilingual blindly performed the back-translation from French to English. This process was reiterated until both English versions were close enough in meaning to consider that the French version was a good translation of the original English version (iterative back-translation). After the process was completed, the French version was field-tested on a small scale to insure that future participants comprehend all items.

\section{Materials}

Paranormal beliefs were measured with a modified version of Tobacyk's (2004) 26-item version of the R-PBS. The R-PBS is a short scale typically used to assess belief in paranormal phenomena. It provides a self-reported measure of degree of belief in seven dimensions (Traditional Religious Belief, Psi, Witchcraft, Superstition, Spiritualism, Extraordinary Life Forms, and Precognition) which allows the researcher to examine the nature of these beliefs and their relations with various psychological constructs. Reliability indices (Cronbach's a) are not reported in Tobacyk (2004); they ranged from .60 to

.87 in Rattet and Bursik's (2001) study and from .53 to .88 in Aarnio and Lindeman's (2005) study. In the present study, the R-PBS was supplemented with additional items. The rationale for including new items was that the psychometric properties of the R-PBS have been challenged in many studies (see above for details). Based on content-related considerations, and on satisfactory measurement parameters as well (e.g., high loadings, high reliability values), a set of seven items purposely selected to be semantically close to the original ones was added. Four of them were taken from Sjöberg and Wahlberg's (2002) scale of paranormal beliefs (Bghosts exist ${ }^{\wedge}$, Bpeople are reborn and learn something new in each life ${ }^{\wedge}$, Bflying saucers do exist ${ }^{\wedge}$ and Bthere are clairvoyants who can see what is happening in another place ${ }^{\wedge}$ ). All of them did a good job as components of a belief in the paranormal factor (labelled Reality of the soul) by contributing to the high reliability (Cronbach's $\alpha$ ) value for this scale. In the same vein, prior research has shown that items on belief in the possibility of contact with spirits and in life after death had strong loadings (.63 and .62, respectively) on a belief in the afterlife factor (Thalbourne and Delin 1993). In addition, three other items were generated (Bcarrying a lucky charm is protecting from misfortunes ${ }^{\wedge}$, Bconducting archeological excavations of the pyramids can bring bad luck ${ }^{\wedge}$, and Bduring dark nights, spirits sometimes are appearing ${ }^{\wedge}$ ). We opted for these items because (1) there are no items in the R-PBS on beliefs in amulets, rituals, or spirits (Lindeman and Aarnio 2006) while they are among the most popular paranormal beliefs (see Vyse 1997, for a review); (2) once generated, items on beliefs in amulets or rituals were associated with good reliability values in Lindeman and Aarnio's (2006) study. All participants completed the entire questionnaire. They were asked to rate the items on an 11-point scale where 0 denoted total disagreement and 10 total agreement.

The Big Five Aspect Scales (BFAS; De Young et al. 2007) was used to measure personality. It is a 100-item self-report measure designed to assess each of the Big Five factors of personality as well as two lower-level aspects of each of them. This measure asked participants to describe themselves according to statements rated on a 5-point scale ranging from 1 (very inaccurate) to 5 (very accurate). Specifically, 195 participants were presented with the 20 items of Neuroticism, 174 participants with the 20 items of Openness/Intellect, 180 participants with the 20 items of Conscientiousness, 118 participants with the 20 items of Extraversion, and 100 participants 
with the 20 items of Agreeableness. ${ }^{1}$ High correlations between each BFAS factor and its counterpart from various Big Five inventories (e.g., the NEO-PI-R, Costa and McCrae 1992) have been reported, thus providing evidence for validity of the BFAS (De Young et al. 2007). In this study, reliability (Cronbach's $\alpha$ ) ranged from .72 to .87 for the factors and from .67 to .83 for the aspects (see Table 3 for details). Comparable values have been reported by De Young et al. (2007). Correlations between the two aspects within each factor of personality were varied (ranging from .11 between Openness and Intellect to .55 between Withdrawal and Volatility) and quite similar to those reported by De Young et al. (2007).

\section{Data Analysis}

All analyses were performed using Mplus (Muthén and Muthén 1998-2012). ${ }^{2}$ We used Confirmatory Factor Analysis (CFA) to test and compare the fit of a number of competing structural configurations of the RPB-S. There were no missing data in any of the subsamples, likely due to the fact that data were collected individually during at-home sessions. For most items, the univariate distribution of the scores differed from normality (skewness and/or kurtosis values $>1.0$ ). Additionally, the multivariate skew and kurtosis tests of fit were both significant $(p<.001)$, revealing a deviation from multivariate normality. Therefore, we estimated the model fit using a Maximum Likelihood estimator (abbreviated MLM in Mplus) with standard errors and a Chi-square statistic that are robust to non-normality (Brown 2006). The MLM Chi-square test statistic is also referred to as the Satorra-Bentler Chi-square $\left(\mathrm{S}-\mathrm{BX}^{2}\right)$. In addition, we followed common practice in using multiple indices of fit and their cut-off values ( $\mathrm{Hu}$ and Bentler 1999); that is, the comparative fit index (CFI) and the Tucker-Lewis fit Index (TLI) (good fit when values are close to .95), along with the Root Mean Square Error of Approximation (RMSEA) and the Standardized Root Mean Square Residual (SRMR) (excellent fit when values are .05 or lower).

To examine the relationship between personality and paranormal beliefs, bivariate correlation and path analyses were conducted. Specifically, to test the differential prediction hypothesis, we conducted a series of four path analyses (one per Big Five factor, except for Agreeableness). For each path model, the direct effects of both aspects of each personality factor on belief in the paranormal were estimated. We then tested the difference in the standardized path coefficients (betas) for significance. As recommended by Brown (2006)

\footnotetext{
${ }^{1}$ Participants were presented with only one set of personality items (corresponding to one factor) for practical reasons (e.g., length of the full questionnaire). There were no significant differences between the five subsamples regarding gender $($ Pearson Chi-square $=.93, \mathrm{p}=.92)$, age $(\mathrm{F}(4,762)=1.07$, $\mathrm{p}=.37$ ) and belief in the paranormal (Tukey's HSD Post-Hoc test for unequal sample sizes revealed no significant pairwise comparison at $\mathrm{p}<.01$ ).

${ }^{2}$ Path diagrams were designed with AMOS 22.
}

for non-normality, p-values and 95\% confidence intervals (CI) of the betas as well as the difference tests (diff test) were obtained by means of 2000 bootstraps. $^{3}$

Data Availability The datasets generated during and/or analyzed during the current study are available from the corresponding author on reasonable request.

\section{Results}

\section{Structure of the R-PBS}

We tested a number of competing models of the R-PBS's factor structure. The first two models were the traditional 7factor model (which consisted of the 26 original items - see Tobacyk 2004, for details) and its 6-factor alternative model (with a combination of Psi and Spiritualism into one factor). Both models were found to provide a less than acceptable fit to the data with values for CFI, TLI, RMSEA and SRMR that were outside the recommended cut-offs. Fit statistics for these models (and the following ones) are shown in Table 1.

Therefore, based on the aforementioned criticism of the RPB-S (see introduction), we investigated a new six factor conceptualization of paranormal beliefs in which Psi and Spiritualism were combined into one factor and which consisted of 21 items. Fourteen items were taken from the R-PBS (while the 12 remaining problematic items were excluded, e.g., Bmind reading is not possible ${ }^{\wedge}$ or Bthere is life on other planets ${ }^{\wedge}$ ) and seven items were new ones. Table 2 presents the model.

Fit indices indicated an excellent fit of this 6-factor model of paranormal beliefs to the data. All primary factor loadings were above .50 and significant at $\mathrm{p}<.01$. Reliability was acceptable for two factors (Extraordinary Life Forms and Superstition) and good or very good for the other factors. Cross-scale correlations showed that the six paranormal belief factors were positively as well as moderately to highly correlated to each other (.43-.82). This pattern of correlations provided empirical support to proceed with a higher-order factor analysis. In this analysis, a single second-order factor indicating a general tendency to believe in paranormal phenomena was specified to account for the correlations among the six factors. The fit of the higher-order factor model was both excellent and equivalent to the fit of the 6-factor model (non-significant difference in S-B Chi-square values). This therefore supported the legitimacy of representing our six paranormal belief factors by a general index of paranormal belief, as did its excellent reliability $(\alpha=.92)$.

\footnotetext{
$\overline{3}$ Bootstrapping is a resampling procedure in which multiple random samples are generated from the original data set. Because bootstrap results (e.g., parameter estimates, standard errors) are averaged across the number of bootstrapped samples - 2000 in the present study - they are likely to yield more accurate estimates.
} 
Table 1 Fit Indices for Various Models of Paranormal Beliefs

\begin{tabular}{|c|c|c|c|c|c|c|}
\hline Models & $\mathrm{S}-\mathrm{BX} \mathrm{X}^{2}(\mathrm{df})$ & CFI & TLI & RMSEA & SRMR & $\Delta \mathrm{S}-\mathrm{Bx} \mathrm{X}^{2}(\Delta \mathrm{df})$ \\
\hline 7-factor model (traditional model of the R-PBS) & $1067.20(277)$ & .884 & .863 & .061 & .059 & \\
\hline $\begin{array}{l}\text { 6-factor model (alternative model of the R-PBS, Psi-Spiritualism } \\
\text { combined into one factor) }\end{array}$ & $1093.70(283)$ & .881 & .863 & .061 & .060 & \\
\hline New 6-factor model of paranormal beliefs & $471.60(173)$ & .941 & .928 & .048 & .049 & \\
\hline Hierarchical model (new model with a global index as a higher-order factor) & $486.97(182)$ & .939 & .930 & .047 & .049 & $\begin{array}{l}15.13(9) \\
\mathrm{p}=.09\end{array}$ \\
\hline
\end{tabular}

$\mathrm{df}=$ degree of freedom. $\Delta \mathrm{S}-\mathrm{BX} \mathrm{X}^{2}=$ scaled difference between the two nested model (hierarchical and new 6-factor) S-BX ${ }^{2}$ values: as the difference test is non-significant, the fit of the two tested models is considered as equivalent

\section{Relationships between Personality Factors and Aspects and Paranormal Beliefs}

Table 3 shows the zero-order correlations between personality factors and aspects and belief in the paranormal.
Inspection of this table provides strong support for our first hypothesis. For each broad domain of personality (except for Agreeableness for which no significant relationship was observed), either aspect had a higher correlation with the general index of paranormal belief than the factor. The same was true

Table 2 Standardized Factor Loadings (Standard Errors), Reliability [ $\alpha$ ], and Cross-scale Correlations of the New 6-factor Model of Paranormal Beliefs

\begin{tabular}{|c|c|c|c|c|c|c|}
\hline & Factors & & & & & \\
\hline Paranormal beliefs & I & II & III & IV & $\mathrm{V}$ & VI \\
\hline It is possible to communicate with the dead ${ }^{\mathrm{a}}$ & $.79(.02)$ & & & & & \\
\hline Ghosts exist ${ }^{\mathrm{b}}$ & $.79(.02)$ & & & & & \\
\hline During dark nights, spirits sometimes are appearing & $.74(.02)$ & & & & & \\
\hline Reincarnation does occur ${ }^{\mathrm{a}}$ & $.67(.03)$ & & & & & \\
\hline People are reborn and learn something new in each life ${ }^{\mathrm{b}}$ & $.61(.03)$ & & & & & \\
\hline Some individuals are able to levitate objects trough mental forces ${ }^{a}$ & $.51(.03)$ & & & & & \\
\hline Carrying a lucky charm is protecting from misfortunes & & $.72(.03)$ & & & & \\
\hline Conducting archeological excavations of the pyramids can bring bad luck & & $.62(.03)$ & & & & \\
\hline The number $B 13^{\wedge}$ is unlucky ${ }^{a}$ & & $.51(.04)$ & & & & \\
\hline The Loch Ness monster of Scotland exists ${ }^{\mathrm{a}}$ & & & $.69(.04)$ & & & \\
\hline The abominable snowman of Tibet exists ${ }^{\mathrm{a}}$ & & & $.63(.04)$ & & & \\
\hline Flying saucers do exist ${ }^{\mathrm{b}}$ & & & $.55(.04)$ & & & \\
\hline There are actual cases of witcheraft ${ }^{\mathrm{a}}$ & & & & $.84(.02)$ & & \\
\hline Black magic really exists ${ }^{\mathrm{a}}$ & & & & $.78(.02)$ & & \\
\hline Witches do exist ${ }^{\mathrm{a}}$ & & & & $.61(.03)$ & & \\
\hline I believe in $\operatorname{God}^{\mathrm{a}}$ & & & & & $.81(.03)$ & \\
\hline There is a devil ${ }^{\mathrm{a}}$ & & & & & $.78(.03)$ & \\
\hline There is a heaven and a hell ${ }^{\mathrm{a}}$ & & & & & $.77(.03)$ & \\
\hline Some psychics can accurately predict the future ${ }^{a}$ & & & & & & $.83(.02)$ \\
\hline Some people have an unexplained ability to predict the future ${ }^{a}$ & & & & & & $.78(.02)$ \\
\hline There are clairvoyants who can Bsee ${ }^{\wedge}$ what is happening in another place ${ }^{\mathrm{b}}$ & & & & & & $.77(.02)$ \\
\hline I. Spiritualism and Psi beliefs & {$[.85]$} & & & & & \\
\hline II. Superstition & .82 & {$[.64]$} & & & & \\
\hline III. Extraordinary Life Forms & .62 & .56 & {$[.61]$} & & & \\
\hline IV. Witcheraft & .82 & .76 & .48 & {$[.79]$} & & \\
\hline V. Traditional Religious Beliefs & .64 & .51 & .43 & .60 & {$[.83]$} & \\
\hline VI. Precognition & .76 & .68 & .48 & .73 & .52 & {$[.84]$} \\
\hline
\end{tabular}

All loadings and correlations are significant at $\mathrm{p}<.01$. Reliability $[\alpha]$ is given in brackets. ${ }^{\mathrm{Ba}}{ }^{\wedge}$ marked items stem from the R-PBS; ${ }^{\mathrm{Bb}}$ marked items stem from Sjöberg and Wahlberg (2002), non-marked items are new ones 
Table 3 Correlations between the Big Five Factors and Aspects and Paranormal Beliefs (Factors and General Index)

\begin{tabular}{|c|c|c|c|c|c|c|c|}
\hline \multirow[b]{2}{*}{ Big Five factors/aspects } & \multicolumn{7}{|c|}{ Paranormal beliefs } \\
\hline & $\begin{array}{l}\text { Spiritualism } \\
\text { and Psi beliefs }\end{array}$ & $\begin{array}{l}\text { Supers- } \\
\text { tition }\end{array}$ & $\begin{array}{l}\text { Extraordinary } \\
\text { Life Forms }\end{array}$ & Witchcraft & $\begin{array}{l}\text { Traditional } \\
\text { Religious Beliefs }\end{array}$ & $\begin{array}{l}\text { Pre- } \\
\text { cognition }\end{array}$ & General Index \\
\hline Neuroticism [.86] $(\mathrm{N}=195)$ & $.18^{*}$ & $.15^{*}$ & .03 & .03 & .00 & .08 & .10 \\
\hline Withdrawal [.79] & $.24 * *$ & $.20 * *$ & .05 & .07 & .02 & .13 & $.16^{*}$ \\
\hline Volatility [.80] & .08 & .06 & .00 & -.02 & -.02 & .02 & .02 \\
\hline Openness/Intellect [.72] $(\mathrm{N}=174)$ & $.16^{*}$ & -.03 & .06 & .12 & $.24 * *$ & .11 & $.15^{*}$ \\
\hline Openness [.68] & $.20 * *$ & .03 & .00 & $.26 * *$ & $.27 * *$ & $.19^{*}$ & $.23 * *$ \\
\hline Intellect [.71] & .04 & -.08 & .08 & -.08 & .08 & -.02 & .00 \\
\hline Conscientiousness [.87] $(\mathrm{N}=180)$ & $-.17^{*}$ & $-.19 *$ & $-.18^{*}$ & $-.19 * *$ & -.02 & -.04 & $-.17 *$ \\
\hline Industriousness [.83] & $-.21 * *$ & $-.21 * *$ & $-.21 * *$ & $-.24 * *$ & -.12 & -.14 & $-.26 * *$ \\
\hline Orderliness [.78] & -.09 & -.12 & -.11 & -.10 & .09 & .07 & -.05 \\
\hline Extraversion [.77] $(\mathrm{N}=118)$ & .15 & $.25^{* *}$ & -.03 & .16 & .17 & .10 & .17 \\
\hline Assertiveness [.69] & .16 & $.30^{* *}$ & .03 & $.21^{*}$ & .18 & .16 & $.21^{*}$ \\
\hline Enthusiasm [.69] & .10 & .14 & -.06 & .08 & .11 & .02 & .08 \\
\hline Agreeableness [.73] $(\mathrm{N}=100)$ & .04 & -05 & -.17 &.-01 & -.07 & .11 & -.02 \\
\hline Compassion [.75] & .10 & -.02 & -.14 & .01 & -.09 & .13 & .01 \\
\hline Politeness [.67] & -.03 & -.06 & -.13 & -.02 & -.02 & .05 & -.04 \\
\hline
\end{tabular}

Reliability $[\alpha]$ of the Big Five factors and aspects is given in brackets

$* \mathrm{p}<.05 ; * * \mathrm{p}<.01$

for the paranormal belief factors. The broad neuroticism factor had a lower (positive) correlation with spiritualism and psi beliefs and superstition than its withdrawal aspect. The (positive) correlations of the broad openness/intellect factor with traditional religious beliefs and precognition, as well as spiritualism and psi beliefs and witchcraft, were lower than its openness aspect. The broad conscientiousness factor correlated (negatively) with all paranormal belief factors less strongly than its industriousness aspect. The (positive) correlations of the broad extraversion factor with superstition and witchcraft were lower than its assertiveness aspect. All significant correlations were small to medium in magnitude (ranging from .15 to .30).

Our second hypothesis posited that the two lower-level aspects of each broad dimension would differentially predict belief in the paranormal. Based on the significant correlations reported in Table 3, we conducted four path analyses to test direct effects of the two aspects within each Big Five domain (except for Agreeableness) on both the general index and factors of paranormal belief. Figure 1 illustrates the resulting path models for the four broad dimensions of personality.

In the path model for the neuroticism domain (Fig. 1, diagram A), from 3 to $6 \%$ of the variance was explained in paranormal belief. Of the two aspects, we observed only significant direct effects from Withdrawal, not from Volatility. Within the openness/intellect domain (diagram B), both aspects accounted for 3 to $8 \%$ of the variance in paranormal belief. However, one can see that only the openness aspect had significant direct effects on the general index and four paranormal belief factors, not the intellect aspect. The path model for the conscientiousness domain explained from 4 to $8 \%$ of the variance in paranormal belief (diagram C). Only the industriousness aspect had significant direct effects on belief in the paranormal. Within the extraversion domain (diagram D), the two aspects contributed to explaining from 4 to $9 \%$ of the variance in paranormal belief. Again, only one aspect, namely Assertiveness, had significant direct effects on belief in the paranormal, not the other one (enthusiasm).

Table 4 shows the detailed statistics for the path modeling of each Big Five domain.

As predicted, in every case, the aspects differentially predicted belief in the paranormal; and, in most cases, the difference test was significant. So, hypothesis 2 may be considered as mostly supported by the data. Specifically, the general index and two factors of paranormal belief were positively and significantly predicted by Withdrawal but not Volatility. Openness but not Intellect emerged as a positive and significant predictor of the general index and four factors of paranormal belief. The general index and four factors of paranormal belief were negatively and significantly predicted by Industriousness but not Orderliness. Finally, the general index and two factors of paranormal belief were positively and significantly predicted by Assertiveness but not Enthusiasm. Across personality domains, the variance explained in paranormal belief was $\mathrm{R}^{2}=9 \%$ at best, indicating that the combined effects of both aspects of each personality domain were modest. 


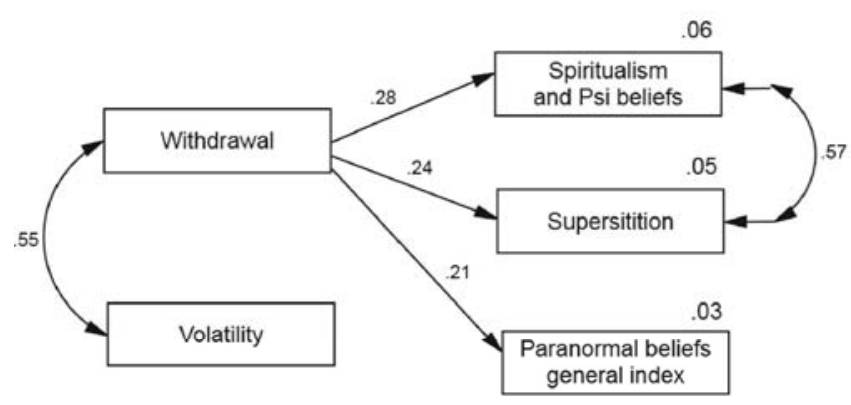

\section{$\mathrm{C}-$ Conscientiousness}

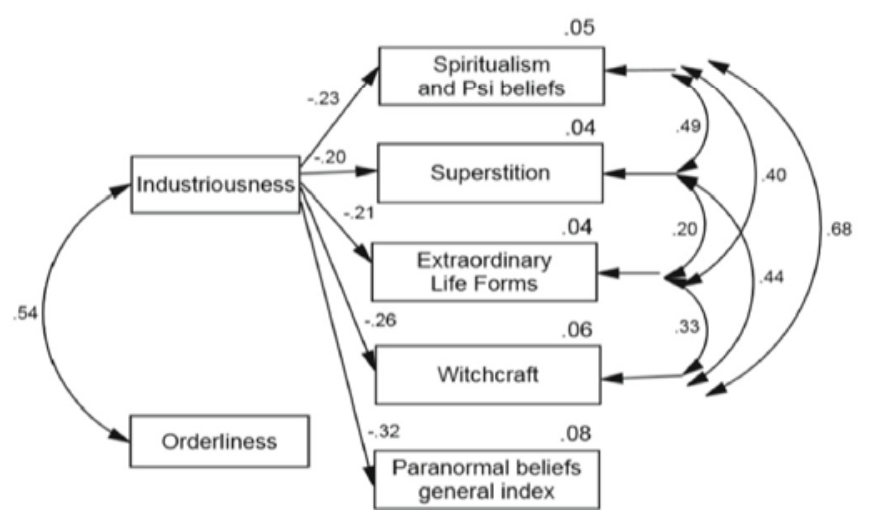

Fig. 1 Path models for Neuroticism (diagram A), Openness/Intellect (diagram B), Conscientiousness (diagram C) and Extraversion (diagram D). The values above one-headed arrows are standardized direct effects $(\beta)$, the values at double-headed arrows are correlations (r), and numbers

\section{Discussion}

The first aim of this study was to identify a psychometrically sound structure of paranormal beliefs, which is a requirement for properly examining the paranormal belief-personality relationship. This step was needed because there is no consensus, but concern, about the construct validity of the leading assessment tool of such beliefs, the Tobacyk's (2004) R-PBS (Lange et al. 2000; Lindeman and Aarnio 2006). Based on the literature, we tested and provided support for a 6-factor model of the R-PBS with a combination of Psi and Spiritualism into one factor and which consisted of 21 items. Conceptually, this merger makes sense because the two factors may reflect the same human paranormal ability; namely, mind over matter. It is also congruent with existing evidence that has indicated a possible mix between these two factors (e.g., Lawrence et al.
B - Openness/Intellect

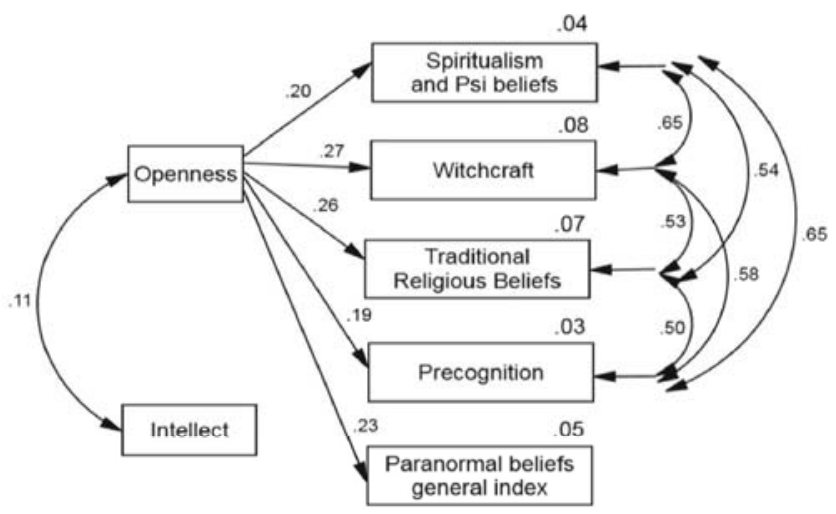

D - Extraversion

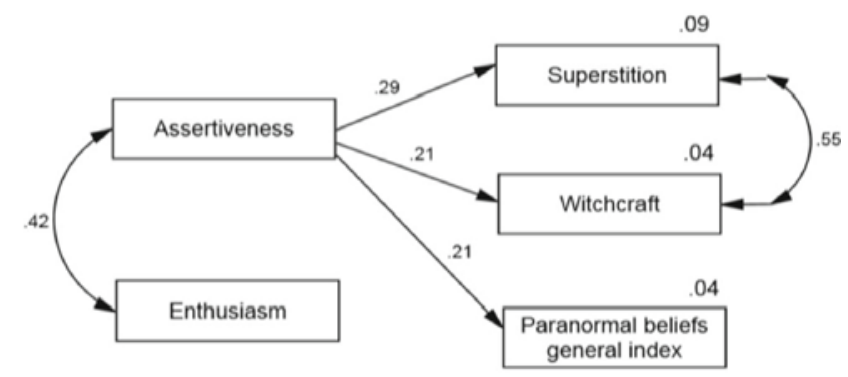

above the rectangles reflect the amount of explained variance $\left(\mathrm{R}^{2}\right)$ of the associated variable by the combination of both aspects. Only significant direct effects (at least at $\mathrm{p}<.05$ ) are shown. Refer to Table 4 for detailed findings

1997). Empirically, compared to the traditional 7-factor model of the R-PBS, this new 6-factor model is associated with better psychometric properties. In addition, the moderate to strong correlations among the six factors allowed us to test and highlight one higher-order factor representing a general tendency to believe in paranormal phenomena. This result is fully in line with the finding from Lindeman and Aarnio's (2006) study of the dimensionality of paranormal beliefs. These authors have brought together a range of beliefs (including paranormal beliefs) and have shown that these beliefs could be best described by one higher-order factor (labelled Magico-religious beliefs), indicating a general tendency to believe in paranormal phenomena.

Having highlighted a valid model for measurement of paranormal beliefs, we were then in a position to pursue the second aim of our study which was to clarify the understanding of the 
Table 4 Standardized Direct Effects $(\beta)$ of the Big Five Aspects to Belief in the Paranormal, Confidence Intervals (95\% CI) of the Standardized Direct Effects, Explained Variances ( $\mathrm{R}^{2}$ ) in Paranormal Beliefs, Betas Difference Tests, and Confidence Intervals (95\% CI) of the Betas Difference Tests

\begin{tabular}{|c|c|c|c|c|c|c|c|}
\hline \multirow[b]{2}{*}{ Big Five aspects } & \multicolumn{7}{|l|}{ Paranormal beliefs } \\
\hline & Spiritualism and Psi beliefs & Supers-tition & Extraordinary Life Forms & Witchcraft & Traditional Religious Beliefs & Precognition & General Index \\
\hline Withdrawal $(95 \% \mathrm{CI})$ & $.28 * * *(.13 .43)$ & $.24 * * *(.09 .39)$ & & & & & $.21 * *(.05 .36)$ \\
\hline Volatility $(95 \% \mathrm{CI})$ & $-.08(-.27 .12)$ & $-.08(-.26 .11)$ & & & & & $-.09(-.27 .09)$ \\
\hline $\mathrm{R}^{2}$ & .06 & .05 & & & & & .03 \\
\hline Diff test $(95 \% \mathrm{CI})$ & $.36 *(.06 .65)$ & $.32 *(.02 .61)$ & & & & & $.30 *(.001 .59)$ \\
\hline Openness $(95 \% \mathrm{CI})$ & $.20 * * *(.07 .33)$ & & & $.27 * * *(.12 .42)$ & $.26 * * *(.10 .42)$ & $.19 *(.04 .34)$ & $.23 * * *(.08 .37)$ \\
\hline Intellect $(95 \% \mathrm{CI})$ & $.02(-.15 .18)$ & & & $-.12(-.28 .05)$ & $.05(-.09 .20)$ & $-.04(-.22 .13)$ & $-.02(-.20 .15)$ \\
\hline $\mathrm{R}^{2}$ & .04 & & & .08 & .07 & .03 & .05 \\
\hline Diff test $(95 \% \mathrm{CI})$ & $.18(-.04 .40)$ & & & $.39 * * *(.15 .63)$ & $.21^{\dagger}(-.01 .42)$ & $.23^{\dagger}(-.02 .48)$ & $.25 *(.01 .49)$ \\
\hline Industriousness $(95 \% \mathrm{CI})$ & $-.23 *(-.42-.05)$ & $-.20 *(-.38-.03)$ & $-.21 *(-.40-.01)$ & $-.26^{* * *}(-.46-.09)$ & & & $-.32^{* * *}(-.50-.15)$ \\
\hline Orderliness $(95 \% \mathrm{CI})$ & $.04(-.14 .22)$ & $-.01(-.19 .16)$ & $.00(-.16 .16)$ & $.04(-.14 .22)$ & & & $.13(-.04 .29)$ \\
\hline $\mathrm{R}^{2}$ & .05 & .04 & .04 & .06 & & & .08 \\
\hline Diff test $(95 \% \mathrm{CI})$ & $-.27^{\dagger}(-.59 .04)$ & $-.19(-.49 .12)$ & $-.21(-.52 .10)$ & $-.30 *(-.59-.01)$ & & & $-.45^{* * *}(-.74-.16)$ \\
\hline Assertiveness $(95 \% \mathrm{CI})$ & & $.29 * * *(.14 .44)$ & & $.21 *(.03 .39)$ & & & $.21 *(.05 .38)$ \\
\hline Enthusiasm $(95 \% \mathrm{CI})$ & & $.02(-.18 .21)$ & & $-.01(-.20 .18)$ & & & $-.01(-.21 .19)$ \\
\hline $\mathrm{R}^{2}$ & & .09 & & .04 & & & .04 \\
\hline Diff test $(95 \% \mathrm{CI})$ & & $.27^{\dagger}(-.03 .58)$ & & $.22(-.10 .55)$ & & & $.22(-.09 .53)$ \\
\hline
\end{tabular}

$\mathrm{R}^{2}=$ percentage of variance explained in paranormal beliefs by the combination of both aspects of each Big Five domain

${ }^{\dagger} \mathrm{p}<.10 ; * \mathrm{p}<.05 ; * \mathrm{p}<.01 ; * * * \mathrm{p}<.005$ 
association between personality and belief in the paranormal. Namely, though the Big Five factors are among the most important correlates of paranormal beliefs (Irwin 2009; Smith et al. 2009), previous studies have been mixed with regard to the magnitude of their relationships (e.g., Wiseman and Watt 2004, versus Willging and Lester 1997, for Neuroticism). To explain it, we argued that some lower-level aspects of the Big Five factors (as defined by De Young et al. 2007) are more conceptually and empirically related to paranormal beliefs than are others. Accordingly, we expected (hypothesis 1) and found that in each broad domain of personality (except for Agreeableness for which, as expected, no significant relationship was observed), one aspect correlated with the general index of paranormal belief as well as paranormal belief factors more strongly than the factor. This finding can clarify some inconsistent results found in the literature (e.g., see Rattet and Bursik 2001). For the most part, research has adopted an omnibus approach to investigate the relations between paranormal beliefs and personality dimensions using various and broadband measures of personality (e.g., MacDonald 2000; Williams et al. 2007). Relying only on one broad measure of personality would weaken or mask in some, but not all, studies (as a function of the measure employed) - some of these relations. To our knowledge, this is the first time that such an explanation is offered for clarifying the apparent incompatibility of findings in the personalityparanormal belief relationships.

Along similar lines, we made a differential prediction hypothesis such that the effect of one aspect would not be the same as another aspect. Consistent with this second hypothesis, our results showed that Withdrawal, Openness, Industriousness, and Assertiveness did a good job of predicting belief in the paranormal, while Volatility, Intellect, Orderliness and Enthusiasm were not predictors of such beliefs. That is, the more the individuals scored high on the withdrawal, openness, or assertiveness aspect, or the less they considered themselves as industrious, the more they believed in the paranormal. Collectively, these findings are consistent with some past research (e.g., Aarnio and Lindeman 2005; Kennedy 2005; Saucier and Skrzypinska 2006). More importantly, by showing that the De Young et al. (2007) aspects of each personality dimension differentially predict paranormal beliefs, this study helps in the understanding of a large number of empirical inconsistencies in the relationships between these variables. From a practical standpoint, our findings emphasize the importance of considering lower levels of the personality hierarchy in attempting to understand paranormal beliefs. This is a major thrust of our study because, as far as we know, it represents the first attempt to document the relationship between personality and belief in the paranormal at an intermediate level of personality structure - between the narrow facets and the broad domains. As a whole, our study extends the recent literature on the merits of considering both broad and narrow representations of each Big Five domain in understanding and predicting personality-related criteria (e.g., De Young et al. 2016).

This study suffers, however, some limitations. First, the direct effects of the ten aspects of the Big Five on paranormal belief could not be simultaneously tested since, for practical reasons, the participants were presented with only one set of personality items corresponding to only one factor and its two lower-level aspects. As a result, it was impossible to generate the complete personality profile of the high paranormal believer (based on the combination of key personality aspects from every broad dimension) mainly because of the possible overlap in variance explained by several aspects. More extensive research using a within-subject design is needed to identify such personality profiles. A second limitation, and also an area for future research, is to include a number of important correlates of paranormal beliefs as potential moderators of the relations between personality factors and aspects and belief in the paranormal. One possible moderator is gender because a myriad of studies have shown that women tend to have more paranormal beliefs than men (e.g., Irwin 1993; Lange et al. 2000). Another interesting moderator could be the cognitive thinking styles because they have repeatedly been shown as important predictors of paranormal beliefs (e.g., Lindeman and Aarnio 2006). Third, although not the scope of the current paper, investigating paranormal beliefs as they relate to the Big Five facets - an even more narrow level of personality structure - would be a fruitful avenue of future research to explore in greater depth the paranormal belief-personality relationships. Fourth, although the results of the study supported the expected patterns of paranormal belief-personality relationships, it should be noted that the strength of association between personality and belief in the paranormal was quite small in many cases. Replication of the present study using a within-subject design (limitation 1), including some important moderators (limitation 2), and measuring personality at the facet level (limitation 3) could provide stronger support for the relationships reported in the current study.

To conclude, this study addressed some key concerns raised in the literature on the R-PBS by identifying an alternative and psychometrically sound structure of paranormal beliefs. This study also provided a more clear view of how people's paranormal beliefs are associated with their personality, by highlighting the differential role of lower-level aspects of each Big Five factor in paranormal beliefs. Only one of the two aspects within each of the Big Five predicts differences in paranormal beliefs, not the other one. Specifically, the withdrawal, openness, industriousness, and assertiveness aspects (of Neuroticism, Openness/Intellect, Conscientiousness and Extraversion, respectively) did a good job of predicting belief in the paranormal, while the volatility, intellect, orderliness and enthusiasm aspects were not predictors of such beliefs. This contributes to refine our 
understanding of how and why people believe in paranormal phenomena, even though future work is needed to fully understand such beliefs. More broadly, using lower-level constructs of personality traits could be very helpful to disentangle, and thus better understand associations between personality and a wide variety of psychological phenomena.

Funding This research did not receive any specific grant from funding agencies in the public, commercial, or not-for-profit sectors.

\section{Compliance with Ethical Standards}

Ethical Approval All procedures performed in this study involving human participants were in accordance with the ethical standards of the institutional and/or national research committee and with the 1964 Helsinki declaration and its later amendments or comparable ethical standards.

Informed Consent Informed consent was obtained from all individual participants included in the study.

Conflict of Interest The authors declared no potential conflicts of interest with respect to the research, authorship, and/or publication of this article.

Publisher's note Springer Nature remains neutral with regard to jurisdictional claims in published maps and institutional affiliations.

\section{References}

Aarnio, K., \& Lindeman, M. (2005). Paranormal beliefs, education, and thinking styles. Personality and Individual Differences, 39, 12271236.

Brislin, R.W. (2000). Some methodological concerns in intercultural and cross-cultural research. In R.W. Brislin (Ed.), Understanding Culture's Influence on Behavior. Fort Worth, TX: Harcourt.

Brown, T. A. (2006). Confirmatory factor analysis for applied research. New York, NY: Guilford Press.

Costa, P.T., \& McCrae, R.R. (1992). NEO PI-R Professional Manual. Odessa, FL: Psychological Assessment Resources.

De Young, C. J., Quilty, L. C., \& Peterson, J. B. (2007). Between facets and domains: 10 aspects of the big five. Journal of Personality and Social Psychology, 93, 880-896.

De Young, C. J., Carey, B. E., Krueger, R. F., \& Ross, S. R. (2016). Ten aspects of the big five in the personality inventory for DSM-5. Personality Disorders: Theory, Research, and Treatment, 7, 113123.

Hu, L., \& Bentler, P. M. (1999). Cutoff criteria for fit indexes in covariance structure analysis: Conventional criteria versus new alternatives. Structural Equation Modeling, 6, 1-55.

Irwin, H. J. (1993). Belief in the paranormal: A review of the empirical literature. Journal of the American Society for Psychical Research, $87,1-39$.

Irwin, H.J. (2009). The psychology of paranormal belief. A researcher's handbook. Hertfordshire, UK: University of Hertfordshire Press.
Kennedy, J. E. (2005). Personality and motivations to believe, misbelieve. and Disbelieve in Paranormal Phenomena. Journal of Parapsychology., 69, 263-292.

Lange, R., Irwin, H. J., \& Houran, J. (2000). Top-down purification of Tobacyk's revised paranormal belief scale. Personality and Individual Differences, 29, 131-156.

Lawrence, T. R., Roe, C., \& Williams, C. (1997). Confirming the factor structure of the paranormal beliefs scale: Big orthogonal seven or oblique five? Journal of Parapsychology, 61, 13-31.

Lindeman, M., \& Aarnio, K. (2006). Paranormal beliefs: Their dimensionality and correlates. European Journal of Personality, 20, 585-602.

Lindeman, M., Riekki, T., \& Svedholm-Häkkinen, A. M. (2015). Individual differences in conceptions of soul, mind, and brain. Journal of Individual Differences, 36, 157-162.

MacDonald, D. A. (2000). Spirituality: Description, measurement, and relation to the five factor model of personality. Journal of Personality, 68, 153-197.

Muthén, L.K., \& Muthén, B.O. (1998-2012). Mplus User's Guide (7 th $^{\text {th }}$ edition). Los Angeles, CA: Muthén \& Muthén.

Rattet, S. L., \& Bursik, K. (2001). Investigating the personality correlates of paranormal belief and precognitive experience. Personality and Individual Differences, 31, 433-444.

Risen, J. L. (2016). Believing what we do not believe: Acquiescence to superstitious beliefs and other powerful intuitions. Psychological Review, 123, 182-207.

Saucier, G., \& Skrzypinska, K. (2006). Spiritual but not religious? Evidence for two independent dispositions. Journal of Personality, $74,1257-1292$.

Sjöberg, L., \& Wahlberg, A. (2002). Risk perception and new age beliefs. Risk Analysis, 22, 751-764.

Smith, C. L., Johnson, J. L., \& Hathaway, W. (2009). Personality contributions to belief in paranormal phenomena. Individual Differences Research, 7, 85-96.

Swami, V., Chamorro-Premuzic, T., \& Shafi, M. (2009). Psychology in outer-space. Personality, individual difference, and demographic predictors of beliefs about extraterrestrial life. European Psychologist, 15, 220-228.

Thalbourne, M. A., \& Delin, P. S. (1993). A new instrument for measuring the sheep-goat variable: Its psychometric properties and factor structure. Journal of the Society for Psychical Research, 59, 172-186.

Thalbourne, M. A., \& Haraldsson, E. (1980). Personality characteristics and sheep and goats. Personality and Individual Differences, 1 , $180-185$.

Tobacyk, J. J. (2004). A revised paranormal belief scale. International Journal of Transpersonal Studies, 23, 94-98.

Utinans, A., Ancane, G., Tobacyk, J. J., Boyraz, G., Livingston, M. M., \& Tobacyk, J. S. (2015). Paranormal beliefs of Latvian college students: A Latvian version of the revised paranormal belief scale. Psychological Reports, 116, 116-126.

Vyse, S. A. (1997). Believing in magic: The psychology of superstition. New York: Oxford University Press.

Willging, B. T., \& Lester, D. (1997). Paranormal beliefs and personality scores of high school students. Perceptual and Motor Skills, 85, 938.

Williams, E., Francis, L. J., \& Robbins, M. (2007). Personality and paranormal belief: A study among adolescents. Pastoral Psychology, 56, 9-14.

Wiseman, R., \& Watt, C. (2004). Measuring superstitious belief: Why lucky charms matter. Personality and Individual Differences, 37, 1533-1541

Zingrone, N.L., Alvarado, C.S., \& Dalton, K. (1998-1999). Psi experiences and the "big five": Relating the NEO-PI-R to the experience claims of experimental subjects. European Journal of Parapsychology, 14, 31-51 